of external input to the class discussions is desired.

Several possible modifications of the POS302-L approach, however, would have more general applicability. This could involve faculty at two or more institutions getting together to coordinate the syllabi and student assignments for a discussion list format. Instead of book reviews, the student discussions could be organized around a series of issues or research questions. The "Virtual Seminar in International Political Economy,' taught by Lev S. Gonick at Arizona State University-West, integrates the use of a discussion list with electronic archives of the course's required readings. ${ }^{3}$ Discussion lists also provide an opportunity for including authors of reading assignments in on the discussions of their works. Textbook authors and editors might also consider organizing discussion lists geared to their books. There are many potential variations of "distance education" applications of Internet; it would have been quite simple, for example, for students at other campuses to participate on POS302-L as a part of an independent study course arranged with professors at their home campus.
Faculty research activities often involve working with faculty at other institutions, building on what they have done, applying their methods and techniques, and submitting work for external evaluation. In contrast, our teaching activities are isolated from colleagues in the discipline and much that we prize in our research endeavorscollegial exchange and cooperation, peer review, methodological sophistication, and accumulation of knowledge-is often neglected in the classroom. Perhaps teaching is not valued as highly as it should be on university campuses for this very reason.

If, or when, it becomes more common that courses are taught on the Internet, there are significant implications for the teaching profession. The Internet will provide opportunities for external evaluation of the students' and instructors' work and broader opportunities for collegial exchanges related to the development of course syllabi and assignments. For better or worse, instructors or groups of instructors may find themselves competing with faculty at other institutions for student subscriptions to their courses as they now do, in a sense, with faculty in other departments at their own institutions.

\section{Notes}

1. The "Political Science List of Lists" contains a comprehensive listing of discussion lists on topics related to politics and political science. It is available on the APSA Gopher at: <gopher://apsa.trenton.edu>.

2. A complete set of the course and discussion list materials, including all of the book reviews and many of the commentaries, are available on the course Gopher archive: <gopher://gopher.ilstu.edu:70/11/depts/ polisci/courses/pos302 $>$.

3. A description of Gonick's seminar, the students' papers and the electronic archives are available on Gopher at: <gopher:// csf.colorado.edu/csf-lists/gpe $>$.

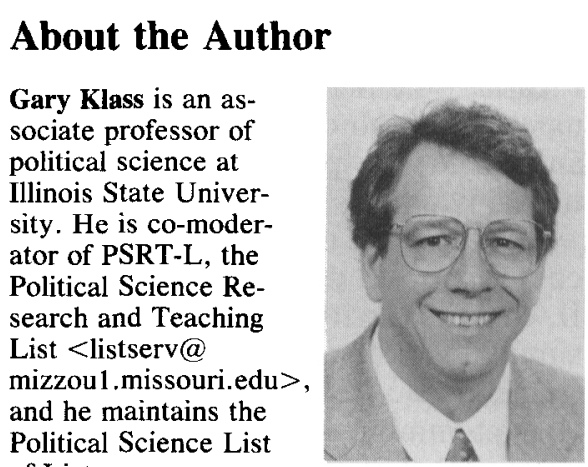
of Lists.

\title{
Poughkeepsie to Persian Gulf Revisited: ICONS, the Internet, and Teaching International Politics
}

\author{
Vernon J. Vavrina, Marist College
}

In the fall of 1990 when the hot spots in the world were Beijing, Baghdad, and Berlin, I was searching for a better way to teach international politics. I stumbled into the fascinating ICONS (International Communication and Negotiation Simulations) program administered by the Department of Government and Politics at the University of Maryland at College Park. ${ }^{1}$ In the December 1992 PS, I reported on my novice's encounter (Vavrina 1992).

Today the hot spots have shift-
ed-Bosnia and Chechnya have stolen the headlines. Yet, I remain firmly convinced that ICONS is a splendid way in which the Internet can be used for better pedagogy (Vavrina 1993).

\section{ICONS: A Brief Summary}

ICONS is a high tech version of a "model United Nations." College students on their home campus do research to role play a particular country's diplomatic delegation. ${ }^{2}$
Via computers and telecommunications they correspond and negotiate with their peers (who are literally scattered around the world at other colleges and universities) ${ }^{3}$ that portray the government missions of other nations. The semester is divided into research, simulation, and debriefing phases. Real-time conferences, in which country-teams from all over the globe negotiate in English on predetermined agenda items, are the highlight (Crookall and Landis 1992; Starkey 1994; Wilkenfeld and Kaufman 1993). 


\section{Hardware/Software}

In 1991 our college was not yet a part of the Internet. We were compelled to pay additional fees for a commercial service to allow us to get to University of Maryland computers. We employed a PC loaded with a communications package, modem, printer, and conventional telephone line. The system worked satisfactorily.

Today our membership in the Internet affords us a cheaper, faster, and more reliable form of communication. Procedures for accessing College Park have been simplified. Students no longer have to learn the commands for the PC's communication software.

I have developed into a fan of the mainframe. Initially, I was enamored with PCs because of their user-friendly nature. Nevertheless, I learned the mainframe environment is not too difficult to negotiate and affords the professor many distinct advantages.

Not the least of these is easy access for my students to POLNET II, the University of Maryland's simulation software. The mainframe is also less prone to problems stemming from computer viruses. More importantly, a mainframe conferencing facility has allowed me to better supervise my pupils. At Marist our IBM 9121 and its software allows any professor to establish electronic class conferences at will. Students in my ICONS class and any other people I authorize may log onto discussion groups specifically geared for the course. ${ }^{4}$ This past year we role played Spain and concentrated on European issues. I had "CONF SPAIN" broken down into "European Union,", "Ethnic Tensions,",

"European Security," "Cross Border Pollution," etc.

A few students were asked to concentrate on each and post research findings. The system recorded who posted what and when. Therefore, I had a permanent written indication of which students had been working hard and which had not. The arrangement allowed students to share easily the fruits of their labors with others. Those who had been accentuating human rights could be quickly advised of their colleagues' work on ecology and vice versa. Conferencing can be expanded by furnishing Spanish majors the opportunity to post English translations of interesting articles that they have read in Latin American periodicals. Potential interdisciplinary synergistic effects are quite appealing.

I insist that my students use e-mail. In fact, I have moved in the direction of a "paperless classroom' - -syllabi, outlines, documents, tests, and instructions can all be distributed electronically. I can do an enormous amount of valuable work from my home.

ICONS is a high tech version of a "model United Nations." College students on their home campus do research to role play a particular country's diplomatic delegation.

Students know that I am carefully monitoring their progress. If they are having difficulty with any of their assignments, they may simply send me quick electronic notes. ${ }^{5}$ I frequently send out short congratulatory messages for pieces of work that are well done. Conversely, I use e-mail to encourage students to improve substandard performances.

LISTSERV discussion groups (Manrique 1992) can be naturally subsumed into a class built around ICONS. Once we were playing the part of Peru. By joining a Peruvianoriented group, a student discovered a wealth of pertinent material which he could rapidly share via e-mail with the rest of the class. I was amazed at the relevance and currency of the information.

\section{The Voice of Experience 6}

Some students will respond poorly to the ICONS course if they are expecting a traditional lecture format and are unwilling to become more active participants in their own learning process. It is imperative to advertise accurately the special nature of this offering before students enroll.

Certain students are thrust into leadership positions in ICONS. From time to time, other classmates find this difficult to swallow. The disgruntled may be prone to react adversely to the entire course unless the instructor judiciously intervenes.

Participants in a typical section may vary from those who know little about technology to those who are very sophisticated. The professor needs to assure individuals who struggle with computers that they will be given any assistance needed.

Students who are deficient in writing skills may learn a great deal from ICONS. They have a motive to construct their messages carefully since their communiques will eventually be read around the world. Students should spell-check and grammar-check their work before it is sent out.?

\section{Problems}

Those familiar with the Internet, LISTSERVS, Gophers, and WWW (World Wide Web) realize their enormous potential for better research and teaching. However, using these tools can frequently be frustrating and time-consuming. Using the Internet is like prospecting for gold. Surely there are tremendous riches to be found; but, there is also a lot of fool's gold or junk. At my institution, Charyl Pollard and Barbara McMullen ${ }^{8}$ have invested many hours building "The Marist 100"-a compilation of electronic academic resources that are reliable and yield satisfying results. ${ }^{9}$

LISTSERV discussion groups have huge academic possibilities. Unfortunately, many who join them are unfamiliar with proper computer etiquette. You would be surprised at the number of people who do not know how to extricate themselves from a list. It is extremely irritating when an otherwise mar- 
velous LISTSERV is cluttered up with frivolous or personal messages.

\section{The Future}

The manner in which I have taught the ICONS course has altered substantially. Things will change even more. Officials at the University of Maryland are currently studying how a program developed at Cornell called $\mathrm{CU}$-See $M e$ may be integrated into ICONS. ${ }^{10}$ This permits transmission of video images over the Internet. At Marist we have established a WWW site which allows a user employing Mosaic ${ }^{11}$ (Wiggins 1994; Wolf 1994) to send and receive text, still pictures, video, and sound across the Information Superhighway. 12

The University of Maryland has also been exploring the possibilities of linking ICONS with conflict resolution training and with history, business, and core curricula. At Marist, we, too, have been mindful of the interdisciplinary advantages of ICONS ${ }^{13}$ by offering the experience to honors students who span fields. ${ }^{14}$

\section{Conclusion}

\section{Nothing that I have learned} throughout the last several years has caused me to change the anticipated and unforeseen benefits of ICONS that I articulated at an earlier date. Participants learn how much work must go into successful summits. They further learn how to use the Internet, LISTSERVS, Gophers, e-mail, and file transfer protocols in an interesting, enjoyable, and memorable way. Continued positive student evaluations are testimony to the unique classroom experience that connecting to the outside world via the Internet and ICONS provides. ${ }^{15}$ As we approach the next century, our challenge is to be the master and not the slave of technology. Not everything that can be technically done is worthwhile. This program is.

\section{Notes}

1. For more information contact: Patty Landis, ICONS Simulation Director, Department of Government and Politics, University of Maryland, College Park, MD 20742. Phone: (301) 405-4171. Fax: (301) 314-9690. Internet: plandis@bss2.umd.edu.

2. I have taught ICONS sections that have ranged in size from 10 to 30 students. Experience has shown that for a school portraying one delegation, the ideal class should be between 15 to 20 participants.

3. The fall 1994 university simulation concentrated on European issues and sported teams that were physically located in Finland, Norway, Russia, Ukraine, Canada, the Netherlands, and the United States.

4. To date, although my students have made abundant use of the conference facility, "outsiders" to the class have been less prone to do so. Our foreign language faculty have from time to time availed themselves of the opportunity to communicate in this fashion. Nevertheless, the potential of the facility has hardly been tapped.

For example, I recently invited an affable diplomat from a major Western European country to visit my ICONS class. He was extremely impressed by what he saw. I resolved that if Marist would ever be given the task of role-playing his country in a future simulation, it would be a good idea to invite him to participate remotely via the Internet. The benefit to my class would be obvious. He, in turn, would probably be fascinated to see how American students would run his country's foreign affairs.

5. Once students become comfortable with e-mail, they do not hesitate to use it. Strong, average, and weak students may actually be more prone to contact the instructor for help in this fashion than through traditional means. Adult students with PCs and modems appreciate the convenience of communicating from home.

6. One thing I have come to know is the importance in having all students learn as early as possible in the semester how to access and master the University of Maryland's POLNET II system. Another important tip is to document concisely and road test thoroughly procedures-such as FTP (file transfer protocols)-that students are apt to find intimidating.

7. Over the years I have found that only a small fraction of students taking the ICONS class have major problems of the nature I have just outlined. Normally, I do not have to devote a lot of time to those who have writing deficiencies or to those who are adjusting to peers in leadership positions. However, a sizable amount of my time is invested in helping students use their computers properly.

Real-time conferences are usually scheduled during nonclass times. Frequently, they occur at off-beat hours. A facilitator should try to attend as many conferences as possible. This in itself is time-consuming.

8. Charyl C. Pollard is a reference librarian in the Marist library. Barbara E. McMullen is Acting Director of Academic Computing at the college.
The professor who wants to utilize ICONS or the Internet in teaching would be well advised to contact corresponding campus officials. The typical instructor is not likely to have the technical expertise of such persons. A strong partnership with the latter is absolutely essential for success.

9. http://www.academic.marist.edu.

10. The author wishes to thank Beth Blake, Acting ICONS Simulation Director for fall 1994, for sharing with me via the Internet some of the future directions of the program. Pre- and post-simulation questionnaires, which are very useful tools for outcomes assessment, will eventually be done electronically.

11. Netscape, WebExplorer, and other WWW browsers may also be used.

12. Marist College has been enormously aided in its efforts to move pedagogy into the twenty-first century by a joint-study arrangement with $1 \mathrm{BM}$.

13. Whenever possible our institution has taken full advantage of the foreign language option by which English messages in the "regular mail" are translated. At Marist we have used with great effectiveness our advanced French or Spanish majors to act as translators.

14. An ICONS class is a viable candidate for a cluster arrangement. Although we have not yet attempted this at my institution, the benefits of doing so are clear. For example, students portraying France could supplement the political science aspects of ICONS by simultaneously enrolling in a relevant package of courses in French language, history, culture, etc.

The University of Maryland offers at College Park periodic workshops for future ICONS facilitators. Marist has sent four faculty (two from political science and two from foreign languages) to attend these highly recommended gatherings. Good teacher training, combined with close collaboration of involved faculty on the home campus, will help to achieve success.

15. Albeit hard to assess, at least some students appear to retain indefinitely the new skills and interests they develop in ICONS. A few maintain memberships in LISTSERV discussion groups well after the semester is over. Some comment that they are now better able to use more powerful research tools in other courses.

\section{References}

Crookall, D., and P. Landis. 1992. "Global Network Simulation: An Environment for Global Awareness." In Global Interdependence: Simulation and Gaming Perspectives, ed. D. Crookall and K. Arai. Tokyo: Springer-Verlag.

Manrique, Cecilia G. 1992. "Network Resources for Political Scientists." PS 25(4): 667-70.

Starkey, Brigid A. 1994. "Negotiation Training Through Simulation: The ICONS International Negotiation Seminars." Educators Tech Exchange (Spring): 6-11.

Vavrina, Vernon J. 1992. "From Poughkeepsie to Peoria to the Persian Gulf: A 
Novice's ICONS Odyssey." PS 25(4): 700-702.

_ 1993. "A Practical Guide to Using ICONS." Presented at the annual meeting of the American Political Science Association, Washington, D.C. Available from ERIC (microfiche: ED 364 473).

Wiggins, Richard W. 1994. "Examining Mosaic: A History and Review." Internet World 5(7): 48-51.
Wilkenfeld, Jonathan, and Joyce Kaufman. 1993. "Political Science: Network Simulation in International Politics." Social Science Computer Review 11: 464-76.

Wolf, Gary. 1994. "The (Second Phase of the) Revolution Has Begun." Wired 2.10 116-54.

\title{
Press Briefings Exercise
}

\author{
Stephen Frantzich, U.S. Naval Academy
}

In this emerging world of "real time" information and media influence, new technology offers us an opportunity to provide our students access to once unavailable information. This press briefings exercise has been used over the last four semesters in courses on the presidency, but would also be appropriate in teaching American government or media and politics. The exercise sensitizes students to the nature of media bias, while opening their eyes to new data sources on the Internet.

\section{Background for Faculty}

Until the electronic age, press briefings were not regularly transcribed, indexed, or archived. There was little or no paper trail to follow when attempting to reconstruct the development of a news story. From formal White House speeches to organized briefings and informal comments or photo opportunities, an increasing number of events are now captured electronically. Access to such transcriptions allows students to almost experience being in the White House for these events.

Students who become familiar with the Internet show considerable facility in going beyond specific assignments and in recognizing its broader utility. While it is legiti- mate to encourage the use of newtechnology cyber surfing-within limits-our specific assignments should be "demand" rather than supply driven. No instructor should introduce a new technology "just because it is there," but rather must justify it on the basis of supporting the teaching of course-relevant content or concepts.

\section{Student Exercise Sheet}

Press coverage of the executive branch of government is highly dependent on regularly scheduled briefings at which press secretaries make prepared statements and answer questions from the press. The most visible of these briefings occur daily in the White House. The permanent White House press corps gathers around the press secretary for an active interchange of information. Most of the information presented is "on the record" which means that it may be quoted and the source given. Other information is presented "off the record," in which case the reporter is not allowed to attribute the source. The press attempts to get more from the press secretary than he or she wishes to divulge, while the press secretary attempts to present the administration in the most favorable light. These brief- ings serve as the raw material for the next day's news.

A number of Internet and commercial on-line services provide full-text access to White House and Agency briefings. While the following exercise will focus on White House briefings, similar analyses could be used in relation to other agency briefings. Full-text access to briefings is a relatively new phenomenon. Until recently, such events were seldom transcribed, indexed, and/or archived. The Clinton White House has considerably accelerated electronic access to both its formal and informal records. Full-text transcripts are almost like being at the event itself.

The purpose of this exercise is to give you a feeling for White House briefings as a news source, and to follow the raw information from the White House into the media. White House press corps refuse to depend on official "handouts" and media events. The briefings serve as a first step, with the journalists selecting the material to cover and augmenting official statements with additional material from other sources.

Your task in this exercise is to identify a specific briefing, comment on its tenor, evaluate its content, and analyze the translation of the briefing material into a major media outlet. As you gather the necessary material, consider the 